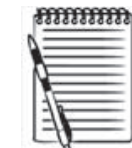

PRESS

RELEASE

\title{
Children's and young people's experience of the National Health Service in England: a review of national surveys 2001-2011
}

\author{
Dougal S Hargreaves, Russell M Viner
}

\begin{abstract}
- Appendix A is published online only. To view this file please visit the journal online (http://adc.bmjgroup.com)
\end{abstract}

Department of General and Adolescent Paediatrics, UCL Institute of Child Health, London, UK

\section{Correspondence to}

D Hargreaves, Department of General and Adolescent Paediatrics, UCL Institute of Child Health, 30 Guilford St, London WC1N 3EH, UK; d.hargreaves@ich.ucl.ac.uk

Accepted 13 July 2011 Published Online First 19 September 2011

\section{(6) OPEN ACCESS}

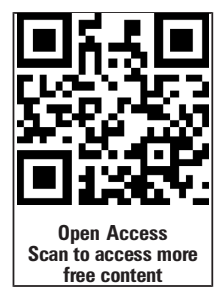

\begin{abstract}
Objectives To investigate what data are available on the National Health Service (NHS) experience of children and young people (0-24 years), and how their experience compares with that of older patients.

Design and data selection Review of 38 national surveys undertaken or planned between 2001 and 2011, identified by the Department of Health (2010). Detailed analysis performed on the most recent completed surveys covering primary, inpatient and emergency care, and children's services.
\end{abstract}

Results Patients under 16 were included in $1 / 38$ national surveys, comprising $<0.6 \%$ of over 10 million respondents. The majority of young people aged 16-24 reported a positive experience of NHS care. However, satisfaction was lower than in older adults. $80.7 \%$ of $16-24$ year olds reported good emergency department care, compared with $89.2 \%$ of older adults (Emergency Department Survey 2008, N=49 $646, \mathrm{OR}=0.51,95 \% \mathrm{Cl} 0.47$ to $0.55, \mathrm{p}<0.001$ ). In the Inpatient Survey $2009,86.5 \%$ of $16-24$ year olds reported good care, compared with $92.7 \%$ of older adults, $(\mathrm{N}=69348, \mathrm{OR}=0.51,95 \% \mathrm{Cl} 0.45$ to 0.57 , $p<0.001)$. Satisfaction with primary care was reported by $83 \%$ of $18-24$ year olds, compared with $90 \%$ of older adults (GP Patient Survey 2009-10 ( $N=2169$ 718, $\mathrm{OR}=0.52,95 \% \mathrm{Cl} 0.51$ to $0.53, \mathrm{p}<0.001$ ). Young people also reported a poorer experience than older adults for their perceived involvement in care, having confidence and trust in their doctor and being treated with respect and dignity.

Conclusions Despite the current focus on services for young people and the importance of patients' views in improving services, the voice of under $16 \mathrm{~s}$ is not included in most national surveys. Despite high levels of overall satisfaction, young adults report a poorer experience of care than older adults.

\section{BACKGROUND}

The Kennedy Report $2010^{1}$ called for a more effective approach to improving health services for children and young people, based on the satisfaction of patients, carers and staff. The principle of listening to and engaging young people is supported by current proposed government reforms to the National Health Service (NHS), ${ }^{2}{ }^{3}$ professional guidance, ${ }^{4} 5$ well-established legal obligations, ${ }^{6}$ and not least, by children and young people themselves. ${ }^{7}$

Yet we know little of their experiences of healthcare, either in the UK or internationally, despite the fact that children and youth under 24 years of age use $36.8 \%$ of emergency department

\section{What is already known on this topic}

- The Kennedy Report (2010) concluded that services for children and young people receive disproportionately low priority in the NHS and often provide mediocre care.

- Recent government policy and the Kennedy Report both emphasise that patient feedback is central to improving the quality of healthcare services.

\section{What this study adds}

- This is the first study which systematically reviews the inclusion and experience of children and young people in national NHS surveys.

- Children and young people under 16 are given little weight in national surveys, comprising $<0.6 \%$ of respondents over the past 10 years.

- Young people 16-24 consistently report poorer experience of care than older adults.

attendances, $19.3 \%$ of inpatient care, $17.8 \%$ of outpatient appointments and up to $40 \%$ of primary care consultations in England. ${ }^{89}$ Services for children and young people are also key to improving the future health of the whole population, as the attitudes and behaviours people develop while young influence their interaction with health services and their decisions about health behaviour throughout their lives. ${ }^{10-12}$

To address this subject, we investigated the extent to which children and young people (aged 0-24 years) have been represented in national NHS surveys between 2001 and 2011, and how their experience of care compares with that of older patients (25+).

\section{METHODS}

We undertook a review of national surveys, comparing the experience of children and young people $(<24)$ with those of older adults $(25+)$ over the past 10 years.

\section{Survey selection}

NHS surveys were identified through 'Liberating the NHS. Transparency in outcomes - a framework for the NHS, ${ }^{\prime 13}$ which reported 38 national surveys that were completed or underway in the period 
2001-2011. Data or reports from these surveys were accessed via the websites of the Care Quality Commission, ${ }^{14}$ the GP Patient Survey, ${ }^{15}$ or the Department of Health. ${ }^{16}$

We recorded the number of times that each type of survey had been undertaken. For the most recent example of each survey, we compared the year, sample size, age range of subjects and age bands for adolescents and young adults in the published reports.

Young people's experience of primary, inpatient and emergency department care are three major areas of concern in recent policy debates. ${ }^{1} 317$ We therefore used the most recent surveys in these areas to analyse young people's experience in more depth.

1. Emergency Department Survey 2008: the dataset with five standard age bands (16-35, 36-50, 51-65, 66-80, 81+) can be accessed via the UK Data Archive (http://www.dataarchive.ac.uk, study number 6329). For our analysis, we used a modified dataset with the lower age band subdivided into four bands (16-19, 20-24, 25-29, 30-35), provided to the authors by the Picker Institute (http://www.pickereurope.org). For details of the methodology see http://www. nhssurveys.org/survey/704.

2. Inpatient Survey 2009: the dataset with five standard age bands can be accessed via the UKDA (study number 6503). We used a dataset with subdivided lower age bands provided to the authors by the Picker Institute. Details of the methodology are available at http://www.nhssurveys.org/ survey/738.

3. GP Patient Survey 2009-10: report was accessed via the GP Patient Survey website (http://www.gp-patient.co.uk/ results/).

One survey included data on patients under 16: the Young Patient Survey 2004, which was confined to inpatient and day care. We compared findings to those from the equivalent questions in the Adult Inpatient Survey from the same year.

4. Young Patient Survey 2004: accessed via the UKDA (study number 5168), details of methodology available at http:// www.nhssurveys.org/survey/656.

5. Adult Inpatient Survey 2004: accessed via the UKDA (study number 5167), details of methodology available at http:// www.nhssurveys.org/survey/314.

\section{Patient experience questions}

For each survey, we analysed up to four questions, which related to feeling involved in care, having confidence and trust in the doctors, being treated with respect and dignity and overall satisfaction with care.
The wording of questions differed minimally between questionnaires. All questionnaires used Likert scales with a range of responses from most positive to least positive experience. For our analysis, we converted each of these scales to a binary outcome (positive/not positive experience of care). For the wording of the questions and the Likert scales used, see online Appendix A.

\section{Analysis}

Adult Emergency Department Survey (2008) and Adult Inpatient Survey (2008-9)

Logistic regression was used to calculate ORs for the four questions above by age band, using over $25 \mathrm{~s}$ as the reference group. ORs with $95 \%$ CIs and p values were calculated, unadjusted and adjusted for the presence of a long-term condition. Results were stratified by sex. Analyses were undertaken using SPSS, version 18 (PASW Statistics 18, Rel, 18.0.0. 2009. Chicago: SPSS Inc).

\section{Young Patient Survey (2004) and Adult Inpatient Survey (2004)}

SPSS was used to calculate the proportion of positive responses to the four questions above for three groups: children (0-11 years) and adolescents (12-17 years) from the Young Patient Survey, and adult subjects (all 16+) from the Adult Inpatient Survey. ORs with $95 \%$ CIs and $p$ values were then calculated by age group, using adult patients as the reference group. Results were stratified by sex.

Although the Young Patient Survey included a small number of subjects aged 18-19, it was designed to investigate views of under 17s and we therefore excluded 18-19-year-old patients from the analysis. For the question about perceived involvement in care, we analysed only responses by the young person or jointly by the young person and parent/carer. For the other questions, all valid responses were analysed, including those by a parent/carer on behalf of the young person.

\section{GP Patient Survey (2009-10)}

The commentary report and technical annex were accessed via the GP Patient Survey website. These report summary data by age band which allowed the calculation of ORs for three of the above questions. Data did not allow stratification by sex, or adjustment for the presence of a long-term condition.

\section{RESULTS}

Characteristics of national surveys 2001-2011 are shown in table 1 . Under 16 s are included in one survey out of 38 , contributing approximately 55000 out of more than 10 million

Table 1 Characteristics of national surveys 2001-2011

\begin{tabular}{|c|c|c|c|c|c|}
\hline Name of survey & $\begin{array}{l}\text { Most recent year } \\
\text { data available }\end{array}$ & $\begin{array}{l}\text { Number of times } \\
\text { survey undertaken }\end{array}$ & $\begin{array}{l}\text { Number of completed } \\
\text { questionnaires in most } \\
\text { recent survey }\end{array}$ & Age of subjects & $\begin{array}{l}\text { Age bands of young adult } \\
\text { in published results }\end{array}$ \\
\hline Maternity & 2010 & 2 & 25363 & $16+$ & $16-18,19-24$ \\
\hline Community mental health services & 2010 & 7 & 17199 & $16+$ & $16-35$ \\
\hline General practice & $2009-10$ & 3 & 2169718 & $18+$ & $18-24$ \\
\hline Adult inpatient & 2009 & 8 & 69348 & $16+$ & $16-35$ \\
\hline Adult outpatient & 2009 & 3 & 72446 & $16+$ & $16-35$ \\
\hline Mental health inpatients & 2009 & 1 & 7527 & $16+$ & $16-35$ \\
\hline Independent sector treatment centre & $2008-9$ & 3 & Approx 14000 & $16+$ & $16-35$ \\
\hline Adult emergency department & 2008 & 3 & 49646 & $16+$ & $16-35$ \\
\hline Ambulance & 2008 & 2 & Approx 4000 & $16+$ & $16-35$ \\
\hline PCT residents registered with a GP & $2007-8$ & 5 & Approx 10000 & $16+$ & $16-35$ \\
\hline Young patient & 2004 & 1 & 62276 & $0-19$ & $12-14,15-17,18-19$ \\
\hline
\end{tabular}


Table 2 Experience of young patients compared with adults in selected surveys 2004-2009

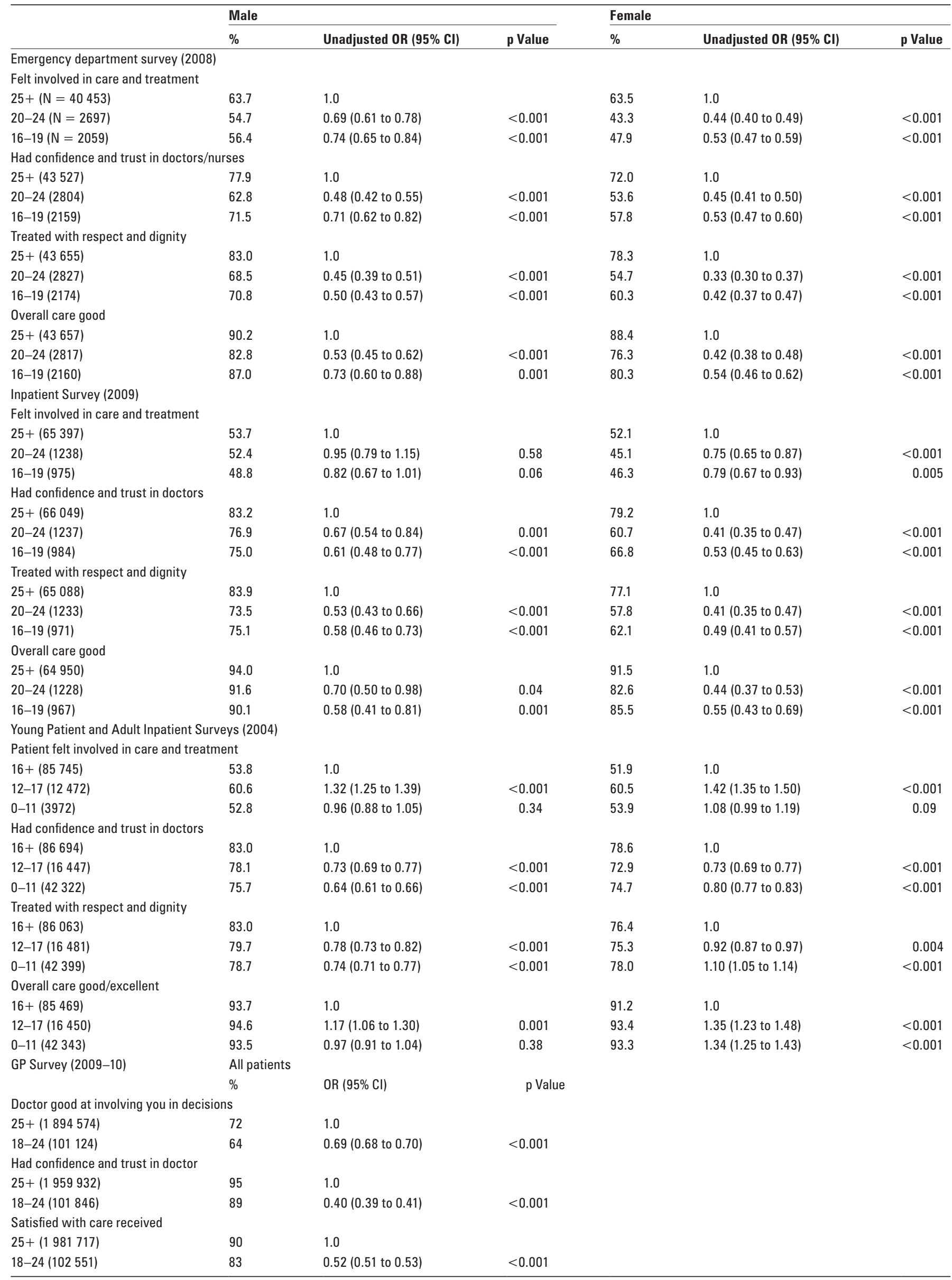


subjects in major national surveys from 2001 to 2011 (<0.6\%). A 6-18-year-old group was included in 35/38 surveys, and over 18 s in $37 / 38$. Data for young adults (16-24s) were presented separately from those for older adults (25+) in 6/37 surveys.

The experience of young patients compared with adults in five national surveys 2004-2009 is shown in table 2 .

In the Emergency Department Survey (2008), the experience of 16-24s was significantly poorer across all four measures of patient care than the experience of over $25 \mathrm{~s}$. There were no material differences in OR or significance when further adjusted for the presence of a long-term condition (data not shown).

In the Inpatient Survey (2009), females aged 16-24 were significantly less likely than older patients to report a positive experience on all four measures of care. Males aged 16-24 reported a significantly poorer experience than older males on most measures, but there was no difference in perceived involvement between patients aged 20-24 and those over 25 . These findings remained unchanged after adjustment for the presence of a long-term condition. Adjustment for the presence of a long-term condition did increase the significance of differences for two questions in males; males aged 20-24 were significantly less likely to report good care than older adults (adjusted $\mathrm{OR}=0.60,95 \%$ CI 0.42 to $0.85, \mathrm{p}=0.004$ ), and $16-19 \mathrm{~s}$ were significantly less likely to report being involved in their care than older adults (adjusted $\mathrm{OR}=0.78,95 \%$ CI 0.63 to 0.96 , $\mathrm{p}=0.02)$.

The GP Patient Survey (2009-10) data showed that the experience of care for 18-24 year olds was significantly poorer than for older patients, across all three measures analysed.

In the 2004 Inpatient Surveys, children and young people were significantly less likely than adults to feel confidence and trust in their doctors or that they were treated with respect and dignity. However, with the exception of males aged $0-11$, young people were more likely than adults to be satisfied with their care overall. Perceived involvement in care was higher in 12-17 year olds than in adults, while there was no significant difference between 0-11 year olds and adults.

\section{DISCUSSION}

Sir Ian Kennedy suggested that satisfaction should be the "single criterion for measuring the quality of the NHS's services for children and young people', ${ }^{1}$ while the English Department of Health says that the principle of direct patient feedback 'is now standard among healthcare systems worldwide'.13 However, we found that the views of under 16s and their families have largely not been included in national surveys, contributing less than $0.6 \%$ of survey respondents since 2001 and none since 2004. Young people aged 16-24 are included in surveys, but rate their care significantly lower than adults across all domains of emergency department and primary care and most domains of inpatient care.

Failure to listen to the views of under $16 \mathrm{~s}$ is not an issue confined to England. We are not aware of any other country that has conducted systematic national surveys which look at young people's experience of healthcare. In many ways, the NHS has been a pioneer in this area, promoting both the voice of patients, through national surveys of adult patients, and the provision of 'adolescent friendly' services, which work in partnership with young people at a local level. ${ }^{18}$ As our data show, NHS services are often good at listening to young people and making them feel involved in their care during individual consultations. However, at the national policy level, there is a clear gap between our findings and the stated aims of professionals and policy makers to listen to young people. The UK is a signatory to the United Nations Convention on the Rights of the Child (1989), ${ }^{6}$ which states an obligation to allow children to express their views and participate in decisions affecting them. Although the government cites 'practical and ethical' difficulties in obtaining the views of children and young people, ${ }^{13}$ we believe these are overstated, with a number of survey tools available to NHS trusts ${ }^{19}$ 20 and much support and guidance available.

National data from other countries on the experience of young adults are also very sparse, despite increasing recognition of the importance of this age group for population health, ${ }^{21}$ and of their specific healthcare needs. ${ }^{22}$

\section{Patient feedback as a measure of healthcare quality}

Key determinants of young people's satisfaction with health services include the ability to listen to and engage them, build confidence and trust, treat them with respect and dignity, and uphold confidentiality. ${ }^{18} 23$ We chose to analyse four questions from the surveys which best matched these concerns.

Patient perceptions are widely regarded as the best source of information on many aspects of care. ${ }^{24}$ Previous research has shown the importance of asking young people themselves, as their perceptions differ from those of their parents, ${ }^{25}$ particularly in perceived involvement in care, communication and confidentiality. ${ }^{26}$ Young people's satisfaction is largely based on provider behaviour and predicts young people's intention to return for follow-up appointments. ${ }^{27}$

However, patient satisfaction clearly has a subjective component and it may be influenced by psychosocial factors. ${ }^{28}$ Where groups have different expectations of healthcare, this may also influence their satisfaction rating. For example, a British study found that South Asian adults were less satisfied with the time they had waited than those from other ethnic groups, despite adjusting for their actual waiting time. ${ }^{29}$ Lastly, questionnaires are less likely to be completed by the most dissatisfied or marginalised groups. Response rates were lower among young people than the over $25 \mathrm{~s}$, and our findings may therefore underestimate the degree of difference between young people and older adults.

The lack of comparable outcome data makes it difficult to compare objective healthcare quality for different age groups. The over 25 age group itself is far from homogeneous and the quality of services for elderly people is high on the political agenda. However, the lower satisfaction of young people is consistent with the Kennedy report findings that services for this age group are frequently 'mediocre', as well as international comparisons which have raised concern about the quality of NHS services for children and young people. ${ }^{30}$

Lastly, standardised questionnaires provide little information about why 16-24 year olds might be less satisfied than older adults. Previous work suggests that a poor experience of transition and difficulty adapting to adult services may be important factors, especially in those with a long-term condition. ${ }^{1}$ However, these data do not allow us to explore the reasons for lack of satisfaction any further.

\section{Strengths and limitations}

This is the first study to examine systematically the evidence of young people's inclusion in national surveys and their experience of healthcare services. It is based on a comprehensive review of national studies by the Department of Health, ${ }^{13}$ 
showing the priorities of policy makers and funding bodies over the past 10 years. All are high-quality studies, with robust methodologies and large sample sizes, providing a reliable guide to patient experience across the NHS.

Analytical limitations largely relate to data availability. We were unable to adjust for the experience of older patients at the same trust (ie, to test whether hospitals serving a young population tend to deliver lower-quality care to everyone). However, even if true, this would mean that the NHS as a whole delivers poorer care to young patients than to older people. There were also specific limitations related to the analysis of each dataset. The public datasets of the Emergency Department (2008) and Inpatient (2009) Surveys do not include a variable or weighting factor for the NHS trust where the patient was treated. Unlike some previously published analyses of inpatient and emergency department data, ${ }^{31} 32$ no such factor was therefore included in our model. As these are national data, from standardised sampling in every relevant NHS trust, there is minimal risk of sampling bias at organisation level, but there may be small effects due to different response rates between trusts. For the Young Patient (2004) and Adult Inpatient (2004) analyses, we were comparing across two different datasets. Therefore, our findings could not be adjusted for the presence of a long-term condition or for the different sampling probability of subjects from different centres (as has been done in one previous published analysis of the Young Patient Survey. ${ }^{17}$ The dataset for the GP Survey (2009-10) is not publicly available and our analysis was therefore based on the published commentary report and technical annex. ${ }^{33} 34$ This prevented analysis by sex or adjustment for the presence of a long-term condition.

\section{CONCLUSIONS}

The views of children and young people under 16 are given disproportionately little weight within the NHS. Although the majority of young people aged 16-24 are satisfied, they consistently report poorer experience of care than older adults. These findings are consistent with a range of expert opinion $^{1}$ and qualitative research with young people, ${ }^{7}$ supporting the view that 'the NHS is designed by older people for older people.' 35

To meet the challenges of the Kennedy Report and the United Nations Convention on the Rights of the Child (1989), policy makers, clinicians, commissioners and managers should ensure that young people's views are heard, building on the success of recent initiatives to improve services for young people. ${ }^{18}$ Further research is needed to guide this process-both qualitative work to understand better young people's experience of healthcare, and quantitative work to improve the quality and quantity of survey data.

Acknowledgements The authors thank Dr Steve Sizmur, Picker Institute Europe, who kindly provided the modified emergency department and inpatient datasets.

Funding This research was carried out as part of a MD (Res) thesis, for which DH was supported by the Department of Health. The research was carried out independently of Department of Health influence. The findings and opinions expressed are the authors' own and are not endorsed by the Department of Health

Competing interests DH was employed as clinical advisor at the Department of Health, March 2009 to March 2011.

Provenance and peer review Not commissioned; externally peer reviewed.

Contributors DH had the original idea for the study, obtained the data and performed the initial analyses. DH and RV were both responsible for study design, drafting the paper, and the integrity and accuracy of the analysis. DH is the guarantor.
Open Access This is an Open Access article distributed in accordance with the Creative Commons Attribution Non Commercial (CC BY-NC 3.0) license, which permits others to distribute, remix, adapt, build upon this work non-commercially, and license their derivative works on different terms, provided the original work is properly cited and the use is non-commercial. See: http://creativecommons.org/ licenses/by-nc/3.0/

\section{REFERENCES}

1. Kennedy I. Getting it Right for Children and Young People: Overcoming Cultural Barriers in the NHS So As to Meet Their Needs. London: Department of Health, 2007.

2. Department of Health. Equity and Excellence: Liberating the NHS. London: Department of Health, 2010.

3. Department of Health. Achieving Equity and Excellence for Children. London: Department of Health, 2010.

4. Wood D, Turner G, Straw F. Not Just a Phase: A Guide to the Participation of Children and Young People in Health Services. London: Royal College of Paediatrics and Child Health, 2010.

5. Office for Standards in Education, Children's Services and Skills. Supporting Young People: An Evaluation of Recent Reforms to Youth Support Services in 11 Local Areas. Manchester: OFSTED, 2010

6. Office of the United Nations High Commissioner for Human Rights. United Nations Convention on the Rights of the Child 1990. Article 12. Geneva: OHCHR, 1990. http://www2.ohchr.org/english/law/crc.htm\#art12 laccessed 24 Feb 2011).

7. Adams L, Ahmad S, Bagnall, et al. 'Nothing About Us, Without Us?' Young People and the Future of the NHS'. London: National Children's Bureau, 2011.

8. Hospital Episode Statistics 2008/9. 5051 842/ 13715787 Emergency Department Attendances. 3120 868/ 16166629 Inpatient Finished Consultant Episodes. 13269 552/ 74729985 Outpatient Appointments. Excludes Episodes with Incomplete Data or No Recorded Age. www.hesonline.nhs.uk. (accessed 27 Sep 2010).

9. Department of Health. Achieving Equity and Excellence for Children. London: Department of Health, 2010.

10. Donaldson L. Under Their Skins: Tackling the Health of the Teenage Nation. Chief Medical Officer's Annual Report 2007. London: Department of Health, 2008.

11. Marmot M. Fair Society, Healthy Lives: Strategic Review of Health Inequalities in England Post 2010. The Marmot Review, 2010. http://www.marmotreview.org/ (accessed 25 Feb 2011)

12. Department of Health. Healthy Lives, Healthy People: Our strategy for Public Health in England. London: Department of Health, 2011.

13. Department of Health. Transparency in Outcomes - A Framework for the NHS. London: Department of Health, 2010.

14. http://www.cqc.org.uk/search.cfm?widCall1=customWidgets.search do 2 \&ocl id filter=EDITORIAL\%2CNEWS\%2CEVENT\%2CSCOPING PAREETT\%2CCOUNCIL\%2CGUIDANCEGsearch _ string=patient+survey (accessed 23 Aug 2011).

15. http://www.gp-patient.co.uk/ (accessed 24 Feb 2011).

16. http://www.dh.gov.uk/en/Publicationsandstatistics/PublishedSurvey/ NationalsurveyofNHSpatients/DH_ 083011 (accessed 24 Feb 2011).

17. Viner RM. Do adolescent inpatient wards make a difference? Findings from a national young patient survey. Pediatrics 2007;120:749-55.

18. Department of Health. You're Welcome Quality Criteria: Making Health Services Young People Friendly. London: Department of Health, 2007.

19. The National Paediatric Toolkit, National Priority Research 2009. www.alderhey. nhs.uk/library/documents/about\%20fabio.doc (accessed 24 Feb 2011).

20. Picker Institute Europe. Young Inpatient Survey 2005. http://www.pickereurope. org/nationalpatientsurveys (accessed 24 Feb 2011)

21. Patton GC, Coffey C, Sawyer SM, et al. Global patterns of mortality in young people: a systematic analysis of population health data. Lancet 2009;374:881-92.

22. World Health Organisation. Adolescent Friendly Health Services: An Agenda for Change. Geneva: WHO, 2002.

23. Royal College of Paediatrics and Child Health. The Intercollegiate Working Party on Adolescent Health. Bridging the Gaps: Health Care for Adolescents. London: Royal College of Paediatrics and Child Health, 2003.

24. Cleary PD. A hospitalization from hell: a patient's perspective on quality. Ann Intern Med 2003:138:33-9.

25. Lindeke L, Fulkerson J, Chesney M, et al. Children's Perceptions of Healthcare Survey. Nurs Adm 0 2009;33:26-31.

26. Byczkowski TL, Kollar LM, Britto MT. Family experiences with outpatient care: do adolescents and parents have the same perceptions? J Adolesc Health 2010;47:92-8. 
27. Freed LH, Ellen JM, Irwin CE, Jr, et al. Determinants of adolescents' satisfaction with health care providers and intentions to keep follow-up appointments. J Adolesc Health 1998;22:475-9.

28. Mah JK, Tough S, Fung T, et al. Adolescent quality of life and satisfaction with care. J Adolesc Health 2006;38:607.e1-7.

29. Mead N, Roland M. Understanding why some ethnic minority patients evaluate medical care more negatively than white patients: a cross sectional analysis of a routine patient survey in English general practices. BMJ 2009;339:b3450.

30. Wolfe I, Cass H, Thompson MJ, et al. Improving child health services in the UK: insights from Europe and their implications for the NHS reforms. BMJ 2011;342:d1277.
31. Garratt E. Inpatient Survey Results 2008. Oxford: Picker Institute Europe, 2009. http://www.nhssurveys.org/survey/738 (accessed 24 Feb 2011).

32. Howell E. Emergency Department Survey Results 2008. Oxford: Picker Institute Europe, 2009. www.nhssurveys.org/survey/704 (accesssed 24 Feb 2011).

33. Ipsos Mori. Technical Annex for the GP Patient Survey 2009/10 Annual Report. London: Ipsos Mori, 2010.

34. Ipsos Mori. Commentary Report for the GP Patient Survey 2009/10 Annual Report. London: Ipsos Mori, 2010.

35. Prof T Stephenson, RCPCH President, 2010. Cited in Kennedy I. Getting it Right for Children and Young People: Overcoming Cultural Barriers in the NHS So as to Meet Their Needs. London: Department of Health, 2010:28. 